\title{
POTENCIAL DISRUPTIVO? A HISTÓRIA DE UMMA BIOTECNOLOGIA
}

\author{
Lorena Bezerra de Souza Matos* \\ Ana Silvia Rocha Ipiranga**
}

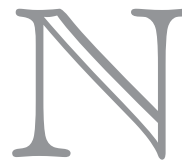

esta pesquisa, busca-se identificar e descrever historicamente o potencial disruptivo de uma biotecnologia vinculada a um laboratório de P\&D da Rede Nordeste de Biotecnologia (Renorbio). Diferentes métodos foram utilizados, com base em uma perspectiva sociológica e com abordagem da análise de relatos e enredos históricos. Considerando as dimensões que fundamentam tecnologias disruptivas, argumenta-se que a biotecnologia justifica a sua potencialidade de disrupção ao articular construtos relacionados à dimensão do capacitador tecnológico. Observou-se que alguns fragmentos dos relatos transitam entre os construtos da dimensão inovação do modelo de gestão, sobretudo após a criação de uma spin-off. Contudo, os construtos que compõem essa dimensão são limitantes, assim como a ausência de relatos relacionados à dimensão sistema de valor comercial, obstando a realização de uma disrupção em todo o seu potencial. Entre as contribuições do artigo releva-se o uso da abordagem histórica no contexto da área da ciência \& tecnologia.

Palavras-chave: Potencialidade de disrupção. Biotecnologia. História. Renorbio.

\section{DISRUPTIVE POTENTIAL? TIEE STORY OF A BIOTECINOLOGY}

Abstrater

\begin{abstract}
his article aims to describe the disruptive potential from the history of biotechnology linked to an R\&D laboratory of the Northeast Biotechnology Network (Renorbio). Different methods were used for the research, based on an analysis approach of historical tales. Considering the basic dimensions underlying the disruptive technologies it is argued that biotechnology justifies its potential disruption to articulate constructs related to the Technology Enabler dimension. On the other hand, it was observed that some fragments of biotechnology tales transiting between the constructs of disruptive dimension - Innovation Management Model, especially after the creation of a new spin-off. However, it is considered that these constructs that comprise the dimension Innovation Management Model are limiting, as well as the lack of tales related to System Commercial Value, hampering the realization of a break in its full potential. It seeks to contribute to theoretical construction in science \& technology area, from a historical approach.
\end{abstract}

Keywords: Disruption potential. Biotechnology. History. Renorbio.

\footnotetext{
* Doutora em Administração de Empresas pela Escola de Administração de São Paulo, Fundação Getulio Vargas, São Paulo, SP, Brasil. E-mail: lorenabmatos@gmail.com

**Doutora em Psicologia do Trabalho e da Organização pela Università degli Studi di Bologna, Bologna, Itália. Professora do Programa de Pós-graduação em Administração da Universidade Estadual do Ceará, Fortaleza, CE, Brasil. E-mail: ana.silvia@pq.cnpq.br
} 


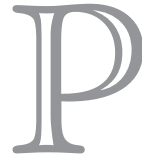

ara Christensen (1997), empresas entrantes, muito embora apresentem uma performance inferior, podem ganhar mercado antes dominado por empresas existentes, ao romper com antigos modelos de negócio, remodelando assim as bases de competição existentes (ADNER, 2002; CHRISTENSEN, 1997; CHRISTENSEN; RAYNOR, 2003).

Nesse sentido, setores altamente baseados em ciência e "alta tecnologia", como semicondutores, comunicação, internet e biotecnologia (HITT, 2005), oferecem reais oportunidades de inovação e de aumento de competitividade para países latecomers, uma vez que possibilitam a exploração de novas oportunidades de negócio, seja no preenchimento de espaço em um mercado novo, seja na conquista de fatias de mercado já consolidado, como é o caso das tecnologias disruptivas.

Desse modo, as tecnologias de disrupção em economias de industrialização recente, como o Brasil, caracterizadas pelo baixo grau de geração de inovações, infraestruturas tecnológicas e industriais precárias, distância dos principais mercados, além de universidades e centros de formação de conhecimento científico e tecnológico nem sempre bem equipados, ocupam lugar de destaque, ao oferecerem potencial de geração de valor e benefícios para a economia nacional.

Considerando essas discussões, o intuito desta pesquisa é contribuir para o desenvolvimento de uma abordagem diferenciada na área da ciência \& tecnologia (C\&T), a partir da identificação e descrição histórica do potencial disruptivo de uma tecnologia da área da biotecnologia, por se tratar de um setor estratégico para o país, uma vez que impacta os principais setores da vida: saúde humana e animal, agricultura, meio ambiente, bioenergia e insumos (FUNDAÇÃO BIOMINAS, 2011).

Os estudos voltados à identificação de tecnologias de disrupção, bem como da apreciação de seu potencial de disrupção, são realizados usualmente baseados na coleta e análise de dados estatísticos e tendências de mercado, requerendo análises econômicas complexas.

Contudo, a historiografia do progresso tecnológico possibilita que sejam visualizados aspectos-chave para o entendimento e compreensão desse processo e, nesse contexto, uma tecnologia deve ser entendida como um processo social, resultante de complexas relações entre fatores e agentes influenciadores, sejam institucionais, econômicos ou tecnológicos (ROSENBERG, 2006).

Nessa linha de discussão, Rabinow (2002) desenvolveu uma pesquisa sobre a história da biotecnologia, partindo da invenção da Reação em Cadeia da Polimerase (Polymerase Chain Reaction - PCR) e das indústrias e instituições a ela associadas, invenção essa que transformou profundamente as práticas e os potenciais de biologia molecular ao identificar e manipular o material genético. Sobre o uso da história na análise das práticas científicas, Rabinow (2002, p. 126) defende que "o objeto do discurso histórico é a historicidade do discurso científico". O autor problematiza esse posicionamento metodológico quando afirma que a ciência "é uma exploração da racionalidade em ação, [...] diversas ciências em ação somente existem em momentos históricos particulares: física não é biologia; a história natural do século XVIII não é a genética do final deste século" (RABINOW, 2002 p. 126).

No contexto da administração da ciência, tecnologia \& inovação (C,T\&I), alguns autores alertaram sobre a persistente negligência relativa à articulação da história nessa literatura. Em particular, citam-se os estudos de Godin (1998, 2006, 2008), nos quais o autor problematiza questões relacionadas aos processos tecnológicos e de inovação por meio do uso da abordagem histórica e de discussões genealógicas de conceitos. Nessa mesma linha, Hoholm e Araújo (2011), ao considerarem esses processos altamente contingentes, confusos e não lineares, propõem analisar as formas em que foram construídos por intermédio de métodos históricos e longitudinais, visando mapear os caminhos complexos e tortuosos dos processos inovadores e tecnológicos.

No Brasil, estudos articulando a abordagem da história vêm sendo desenvolvidos em diferentes áreas da Administração. No contexto dos Estudos Organizacionais 
relevam-se os estudos de Vizeu (2010), Costa, Barros e Martins (2010), Barros (2014a) e Barros e Carrieri (2015), enfatizando a compreensão histórica do fenômeno organizacional e suas especificidades em diferentes setores. Outros estudos vêm sendo desenvolvidos especificamente no contexto da ciência e tecnologia (C\&T), como os de Ipiranga (2010) e Ipiranga e Matos (2014).

Assim, esta pesquisa pretende contribuir para essa linha de estudos, ao abordar a literatura relativa a esses processos, com base em uma perspectiva sociológica, articulando ainda a abordagem histórica sobre tecnologias disruptivas. Nesse sentido, delimitou-se como objetivo deste estudo identificar e descrever historicamente o potencial disruptivo de uma biotecnologia denominada "Desenvolvimento de vacinas contra o vírus da dengue utilizando um sistema vegetal como biofábrica". Essa biotecnologia foi desenvolvida no laboratório de pesquisa e desenvolvimento (P\&D) de Bioquímica Humana da Universidade Estadual do Ceará (UECE), vinculado à Rede Nordeste de Biotecnologia (Renorbio).

A Renorbio, rede do setor biotecnológico formada por instituições de ensino, laboratórios de P\&D e empresas (aproximadamente 40 instituições), visa à consolidação de núcleos de excelência em biotecnologia na região Nordeste, bem como ao estabelecimento e estímulo da massa crítica de profissionais, com competência em biotecnologia e áreas afins, para executar projetos de pesquisa, desenvolvimento e inovação (PD\&I) de importância para o desenvolvimento do Nordeste (RENORBIO, 2013).

Segundo a Organização Mundial da Saúde - OMS (2014), a dengue pode afetar 390 milhões de pessoas/ano. Estudos apontam um custo médio de US\$ 1.500 por paciente com dengue e 18,9 dias de trabalho perdidos (OMS, 2014). No cenário nacional, o Brasil se encontra entre os 30 países mais endêmicos e, apenas no ano de 2013, o país gastou em ações de combate mais de $R \$ 2$ bilhões ao sofrer o maior surto da doença com aproximadamente 2 milhões de casos notificados (BRASIL, 2016).

Afora os impactos socioeconômicos nacionais e internacionais, a biotecnologia ainda vence a impossibilidade de se fabricar vacina contra a dengue usando métodos tradicionais, uma vez que a doença se manifesta em quatro sorotipos semelhantes, porém diferentes entre si (SCHMITZ et al., 2011). Assim, as pesquisas em biotecnologia têm como objetivo potencial combater os quatro sorotipos do vírus da dengue, incluindo o hemorrágico, representando uma tecnologia com potencial inovativo estratégico para o país.

Considera-se ainda que o setor nacional de vacinas é caracterizado por uma dependência do mercado externo. Além disso, os estudos sobre a atuação estatal e o setor nacional de vacinas são escassos, abordando questões relacionadas a uma concepção tradicional de saúde pública e não considerando questões de mercado e de competição. Assim, o estudo sobre os esforços e estruturação de espaços privados para a oferta de vacinas é um ponto que demanda reflexões sobre o campo nacional da saúde (FUNDAÇÃO BIOMINAS, 2011).

Nesse contexto, a questão guia que orienta a problemática da presente pesquisa foi: qual o potencial de disruptura da biotecnologia "Desenvolvimento de vacinas utilizando um sistema vegetal como biofábrica"?

Em função da natureza do problema, realizou-se uma pesquisa do tipo descritiva e com um viés histórico. Considerando especificamente o objeto deste estudo, qual seja, o potencial disruptivo de uma biotecnologia, Barnes, Bloor e Henry (1996) justificam o uso da perspectiva histórica ao enfatizarem como e por que a análise sociológica se torna um complemento essencial no processo de compreensão do conhecimento científico e, nesse contexto, sugerem os autores, o método principal deve se basear na apresentação de estudos de casos históricos.

Nas próximas seções serão articulados os conceitos e as principais dimensões envolvidas na compreensão das tecnologias disruptivas. Após, apresentam-se os procedimentos metodológicos, seguidos dos relatos e enredos da história da biotecnologia sob estudo. Na última seção estão as considerações finais do estudo. 
O vocábulo "disrupção" remete à ideia de ruptura, rompimento, fratura. No campo da administração, o termo foi criado por Clayton M. Christensen, professor de management da Harvard Business School, nos Estados Unidos, em seu artigo "Disruptive technologies: catching the wave" (BOWER; CHRISTENSEN, 1995). Para o autor, uma tecnologia disruptiva seria uma estratégia de inovação de produto, processo/serviço e/ou modelo de gestão que consiga deslocar os líderes de mercado, ao conquistar um segmento ainda não alcançado em mercado já existente.

A teoria das tecnologias disruptivas esclarece o processo pelo qual empresas que miram margens de lucro menores oferecem produtos e serviços mais baratos, simples e eficientes, tornando-os acessíveis (low-cost solutions). A estratégia disruptiva faz com que produtos e serviços, que antes eram disponíveis apenas para consumidores dos segmentos mais altos dos mercados, passem a incluir diferentes faixas e novos consumidores, deslocando os big players de mercado.

Dimensões e comstrutos básicos dlos processos dle disirupȩão

Christensen, Grossman e Hwang (2009) apontam que o processo de disrupção é constituído por três dimensões principais que permitem que problemas fundamentais de um setor sejam tratados a menores escala, custo e capacidade humana do que o comumente exigido. A primeira dimensão é um Capacitador tecnológico (tecnologia sofisticada que tem por intuito simplificar). A segunda dimensão é uma Inovação do modelo de gestão, oferecendo aos consumidores soluções disponíveis e acessíveis. A terceira dimensão é o Sistema de valor comercial, formado por uma cadeia de valor inteiramente nova.

Um capacitador tecnológico permite que problemas básicos de um setor em específico sejam resolvidos com menores dispêndios de escala, custos e recursos humanos, sendo, portanto, a espinha dorsal dos modelos de gestão de disrupção (CHRISTENSEN; GROSSMAN; HWANG, 2009). Os autores citam a área da saúde como exemplo, mostrando que o setor está carregado de novas tecnologias, algumas dessas resultantes de anos de pesquisas e investimentos em laboratórios de P\&D, outras licenciadas em todo ou em parte, e ainda há aquelas adaptadas de um setor produtivo distinto. Nesse sentido, vultosos gastos na área da saúde em economias desenvolvidas, bem como em economias em desenvolvimento, decorrem da incapacidade de diagnosticar com precisão doenças ou ainda se o tratamento é realizado tendo como base o método de tentativa e erro, e não as reais causas da doença, se genéticas, infecciosas ou mesmo desconhecidas.

Para Christensen (2012), após a identificação de um capacitador tecnológico, é necessário elaborar uma estratégia adequada para a sua comercialização, voltando-se assim os esforços para a análise do contexto organizacional. Nesse ponto, avalia-se o modelo de gestão mais estratégico, entre mudar os valores e a cultura da organização principal e/ou criar uma nova organização (CHRISTENSEN, 2012). Conforme o entendimento de Christensen, Grossman e Hwang (2009), um modelo de gestão é um sistema independente formado por quatro elementos principais: i) proposição de valor; ii) fórmula de lucro; iii) processos organizacionais, e; iv) recursos.

Para o autor, o ponto principal para um modelo de negócio é sua proposição de valor (the value proposition), ou seja, "um produto ou serviço que permita aos clientes visados dar conta da tarefa que tentam realizar de uma maneira mais eficiente, conveniente e acessível" (CHRISTENSEN; GROSSMAN; HWANG, 2009, p. 47). No entanto, para que as empresas consigam oferecer essa proposição de valor aos clientes, é necessário que os gestores utilizem a vasta gama de recursos (resources) da organização, como pessoas, instalações, aportes financeiros, produtos, equipamentos, treinamentos, estrutura de custos, padrões, entre outros.

A utilização dos recursos a fim de se obter uma proposição de valor somente é conseguida mediante os processos organizacionais (processes), no sentido de que 
são as formas habituais de trabalho que determinam como os recursos deverão ser combinados. Como resultado dessa combinação resulta a fórmula de lucro (profit formula), definidora das margens de lucro, preços e os aportes necessários para custear a utilização de recursos e processos requeridos para a proposição de valor.

Ocorre que as empresas só podem oferecer ao mercado as proposições de valor que se adéquam aos recursos, processos e fórmula de lucro da organização, ou seja, os gestores só podem adotar novas tecnologias por meios que suportem o modelo de gestão dentro do qual operam (CHRISTENSEN; GROSSMAN; HWANG, 2009). Nesse sentido, os mesmos construtos principais que compõem um modelo de gestão podem ser limitantes para a realização disruptiva de uma tecnologia em todo o seu potencial.

Logo, uma gestão que não contemple a necessidade de mudanças, finda por acomodar-se às velhas estruturas estáveis, culminando assim em perda de vantagem competitiva. Para Henderson e Clark (1990), além do reconhecimento das mudanças a serem feitas, são necessárias sua construção e aplicação no contexto das diferentes dimensões organizacionais. Acontece que esse processo não é simples, uma vez que demanda tempo, recursos e processos de aprendizagem diferenciados, necessitando, portanto, de maestria e sensibilidade por parte dos gestores.

Nesse sentido, para Christensen (2012), organizações pequenas e independentes como spin-offs ou startups seriam apropriadas quando se confrontam com uma tecnologia disruptiva, uma vez que possuem uma forma de organização especialmente adaptada à rede de valor emergente na qual estas se inserem. Por startup, entende-se uma empresa nova, que lida com projetos inovadores de alto risco, envolvendo intensa atividade de P\&D e que tem como principal objetivo a viabilização do desenvolvimento e/ou comercialização de uma tecnologia (DECLEYN; BRAET, 2009). Por serem empresas emergentes, com baixo custo de manutenção, possuem alta flexibilidade e versatilidade, o que Ihes permite uma movimentação estratégica em cenários de incerteza, pois, não há certeza de que ideias e/ou projetos obterão sucessos de mercados.

Assim, as startups figuram como uma estratégia para entrada nesses "oceanos azuis" (KIM; MAUBORGNE, 2005), uma vez que são empreendimentos com baixos custos iniciais, mas que possuem uma alta expectativa de crescimento e escala. Ser escalável, portanto, é a chave de uma startup, uma vez que seu crescimento não necessariamente altera seu modelo de negócio. Assim, ao se tornar escalável, gera-se uma empresa altamente lucrativa.

Por fim, a terceira dimensão de disrupção elencada pelos autores versa sobre um novo sistema de valor comercial, que consiste em uma cadeia de valor completamente distinta da precedente vinculada aos novos modelos de gestão então surgidos (CHRISTENSEN; GROSSMAN; HWANG, 2009).

Tomando como analogia um sistema de saúde, e conforme discutido por Christensen, Grossman e Hwang (2009), a fragmentação de um sistema de valor comercial é complexa, uma vez que requer a mobilização de vários atores conjuntamente, necessitando assim de um nível alto de integração entre médicos, hospitais, empresas, agências e ministérios. O ponto mais difícil é conseguir mover os líderes do sistema vigente, haja vista as muitas barreiras regulatórias que obstam o processo, podendo levar décadas para a transição.

Assim, se e quando uma curva de disrupção no mercado progredir a ponto de satisfazer o nível, bem como a natureza do desempenho tecnológico oferecido pelo outro sistema comercial, a tecnologia de disrupção poderá invadi-lo com velocidade surpreendente, alterando a configuração do sistema comercial então vigente (CHRISTENSEN, 2012).

Por fim, ressaltamos que as tecnologias de disrupção são analisadas, de modo geral, sob uma perspectiva econômica, mais técnica, deixando em segundo plano as microanálises baseadas em suas condições histórica e social, que podem revelar controvérsias e aspectos fundamentais subjacentes ao processo de disrupção. Assim, pretende-se analisar o potencial de uma específica tecnologia disruptiva no setor da biotecnologia, a partir de uma perspectiva sociológica com base nos seus fundamentos históricos. Para tanto, no item seguinte será apresentado e justificado o arcabouço metodológico. 
Em função da natureza do problema outrora apresentado, realizou-se uma pesquisa do tipo descritiva e com um viés histórico, com abordagem predominantemente qualitativa. A inserção da perspectiva histórica na área da administração é constituída por múltiplos posicionamentos epistemológicos, contribuindo para o avanço da área, ao promover a geração de novas abordagens, noções e percepções mais amplas e reflexivas com relação aos objetos de estudo, inclusive no Brasil (COOKE, 1999; BOOTH; ROWLINSON, 2006; ÜSDIKEN; KIESER, 2004; VIZEU, 2010; BARROS; CARRIERI, 2015).

Considerando o objeto deste estudo, enfatiza-se que a historiografia de um processo tecnológico possibilita que sejam visualizados aspectos-chave para o seu entendimento e compreensão (ROSENBERG, 2006). Como afirma o autor: "A tecnologia deve ser entendida como um processo social. A história das invenções não é, decididamente, a história dos inventores", pelo contrário, o progresso tecnológico é o resultado de complexas relações entre fatores e agentes influenciadores desse processo, sejam institucionais, econômicos ou tecnológicos (ROSENBERG, 2006, p. 87).

Jones e Zeitlin (2007) também discutiram sobre o uso da pesquisa histórica na área dos negócios, enfatizando a importância do entendimento das mudanças no decorrer do tempo e iluminando não apenas a evolução dos sistemas administrativos, mas também as suas interações com seus contextos político, econômico e social.

Defende-se, portanto, a utilização da abordagem histórica para o presente estudo, uma vez que essa perspectiva pode contribuir para ampliar a compreensão de processos tecnológicos na área da C\&T ao considerar as interações culturais e históricas entre organizações, redes industriais e setores econômicos (GODIN, 2006; HOHOLM; ARAÚJO, 2011; IPIRANGA; MATOS, 2014).

Além da perspectiva histórica, seguindo orientações de Alvesson e Sandberg (2011), foram considerados os seguintes procedimentos para a consecução metodológica: no primeiro momento foi identificado um domínio da literatura desenvolvida na área da C\&T no contexto da administração, com base em uma ampla revisão bibliográfica sobre o tema. Nessa revisão, foram selecionados autores que abordaram o tema específico das tecnologias disruptivas, inclusive e a partir da perspectiva histórica enquanto método.

Em um segundo momento, foi escolhida uma disciplina - a biotecnologia - e uma situação - laboratórios científicos no Brasil - ligadas à Rede Nordeste de Biotecnologia (RENORBIO, 2013). Entre esses laboratórios se destacou o Laboratório de P\&D de Bioquímica Humana que atualmente desenvolve a biotecnologia sob estudo denominada "Desenvolvimento de vacinas utilizando um sistema vegetal como biofábrica".

Como apontado por Croce (2004), uma narrativa só se torna histórica a partir da exposição crítica de documentos. Para a presente investigação, o corpus histórico documental foi composto por diferentes materiais, envolvendo o levantamento da documentação indireta e direta em uma base de dados de arquivos heterogêneos. Durante o período de 11 meses (março de 2012 a janeiro de 2013), foram ainda realizados procedimentos observacionais dentro do laboratório de $P \& D$, assim como participações nas reuniões para definição do escopo da proteção da biotecnologia. Os registros desses momentos da pesquisa foram realizados em forma de anotações no diário de campo. Como sugerido por Spradley (1980, p. 69-72), foram realizadas notas nas formas de relatos condensados, relatos ampliados das impressões das entrevistas, protocolos sobre o trabalho de campo, notas sobre análises e interpretações imediatamente após o contato com o campo. Consideram-se ainda os seguintes documentos que fundamentaram a análise: relatórios de pesquisa, equipamentos, materiais e cadernos do laboratório de $P \& D$, informações tecnológicas em boletins especializados, patentes e documentos institucionais da base de dados da Renorbio e da spin-off - Greenbean.

Em um segundo momento, como complemento à composição desse arquivo histórico documental, foi realizado um mapeamento das tecnologias no contexto mundial voltadas à área de vacinas por meio dos softwares online Questel Orbit e Silobreaker. 
Segundo Barros (2014b), as mudanças provocadas pela web e pelas tecnologias de informação, como os aumentos da capacidade de armazenamento, da difusão de registros e da redução de custos, ocasionaram transformações na pesquisa com fontes históricas. As relações existentes na construção e na preservação de arquivos se alteram, permitindo-se novas formas de ver o que se considera pesquisa (GILL; ELDER, 2012). A utilização de arquivos de internet na pesquisa permitiu a elaboração de reflexões mais amplas sobre o objeto em estudo, possibilitando a caracterização de possíveis tendências disruptivas, bem como de suas dinâmicas sociais e econômicas.

Nesse sentido, e considerando a ideia de "laboratório extenso" (CALLON, 1989), foram ainda rastreadas as relações existentes entre os atores e instituições externas ao laboratório sob estudo, compondo assim um painel de atores-chave. Dessa forma, um conjunto de entrevistas em profundidade em diferentes momentos da pesquisa e com diferentes atores foi realizado, entre estes: a cientista-coordenadora do laboratório de $P \& D$ e a sua assistente de pesquisa. Enquanto instituições adjacentes e externas ao laboratório, foram envolvidas na pesquisa a Rede de Núcleos de Inovação Tecnológica do Estado do Ceará - Redenit/CE, sobretudo nas questões relacionadas ao processo de proteção e comercialização de tecnologias, e, assim, entrevistou-se o coordenador da Redenit. Foi também entrevistada a representante comercial da Greenbean, a spin-off ligada ao laboratório de P\&D sob estudo e integrante da Renorbio. As entrevistas foram autorizadas para gravação, sendo posteriormente transcritas para a constituição e análise dos relatos e enredos.

O método histórico é um método narrativo que trata de uma dimensão mais subjetiva da realidade social (COOKE, 1999), cujo procedimento de análise se baseia em relatos e enredos que devem ser construídos com base nos objetivos da pesquisa e observando uma periodização no tempo. Nesse sentido, o corpus construído na pesquisa empírica foi analisado mediante o confronto com a base teórica relacionada aos construtos das três dimensões envolvidas no processo de disrupção. Assim, tais construtos foram identificados com base na codificação aberta (COFFEY; ATKINSON, 1996), após diversas leituras e revisões do material empírico organizado.

A apresentação dos resultados e discussões foi organizada na forma de relatos, observando-se as passagens históricas no período de tempo relacionado aos anos de 2004 - 2014, estando esse período caracterizado da seguinte forma: i) 2004-2010 - busca de soluções para o problema de saúde pública da dengue; ii) 2005-2012 processo de patenteamento da biotecnologia; iii) 2010-2014 - criação da spin-off Greenbean e de sua rede de atores.

\section{Contextrulização dla biotecnologia sob estudlo}

A biotecnologia, objeto desta pesquisa, delimita-se no contexto multidisciplinar da Imunologia, Biologia Molecular e Biotecnologia e foi desenvolvida no Laboratório de P\&D de Bioquímica Humana integrante da Renorbio. A biotecnologia desenvolvida pela cientista bioquímica - coordenadora do laboratório de P\&D - tem por finalidade a criação de vacina vegetal contra o vírus da dengue, produzida com proteínas recombinantes em modelo procarionte para os quatro sorotipos do vírus dengue, utilizando plantas como biofábricas de produção dessas proteínas. No processo de patenteamento, a tecnologia recebeu o título "Processo de produção de proteínas do vírus da dengue em plantas, e uso de proteínas na preparação de vacina contra a dengue" (GUEDES et al., 2011).

A biotecnologia estudada visa à preparação de vacinas contra a dengue, com a produção de proteínas do vírus da dengue utilizando sistemas vegetais como biofábrica. O uso de sistemas vegetais para a produção de vacinas tem se mostrado uma alternativa atrativa aos sistemas de produção tradicionais (GHARELO et al., 2016).

Os vírus da dengue (DEN) pertencem à família Flaviviridae, gênero Flavivirus, e ocorrem de quatro sorotipos antigenicamente relacionados, mas distintos entre si, DEN - 1, 2, 3, 4. Dentre as proteínas expressas pelo vírus dengue, a existente no envelope (E) é a única que provê anticorpos neutralizadores, ou seja, é o principal imunógeno para a neutralização do vírus, sendo também a única que permite a entrada 
do vírus na célula do hospedeiro. Por essas razões, a proteína $\mathrm{E}$ tem sido extensamente estudada na área de biotecnologia (GUEDES et al., 2011).

$\mathrm{Na}$ tecnologia, conforme relatado pela cientista, a proteína $\mathrm{E}$ é obtida das folhas da Vigna Unguiculata L (feijão-de-corda), utilizadas como imunógenos protetores contra a dengue. Assim, para a obtenção dessas proteínas, foram utilizadas técnicas de biologia molecular nos vírus dengue e CPMV (Cowpea Mosaic Virus) - genoma do vírus da planta (mosaico Caupi), que apresenta altas taxas de desenvolvimento em seu hospedeiro natural.

Ao ser realizado o estudo histórico e prospectivo de vacinas contra a dengue mediante o software Questel Orbit, verificou-se que o uso de sistemas vegetais como biofábrica se mostra como uma técnica promissora ao proporcionar custo barato, simplicidade no processo de produção, produção em alta escala, além de ser uma técnica biologicamente segura (Notas de campo, pesquisa histórica e prospectiva no mercado de vacinas com o software online Questel Orbit). Nesse sentido, a tecnologia em estudo permite a inserção das sequências de DNA do vírus dengue para a produção de proteína do envelope do vírus dengue (proteína E), sem a necessidade de obtenção ou uso de plantas transgênicas.

Assim, a biotecnologia sob estudo visa, por meio do sequenciamento genético, isolar e clonar do fragmento referente ao domínio III da proteína $\mathrm{E}$ do vírus dengue peptídeos que foram inseridos no DNA do vírus do mosaico do caupi (CPMV) e inoculados em folhas de Vigna Unguiculata (feijão-de-corda), sete dias após a germinação. A planta é então mantida em casas de vegetação por aproximadamente 21 dias, até o surgimento dos sintomas característicos do vírus CPMV e, posteriormente, são extraídos peptídeos derivados da proteína E com características imunogênicas (Notas de campo, processo de fabricação, baseadas nas anotações dos cadernos de laboratório).

De acordo com a cientista-coordenadora responsável pelo desenvolvimento da biotecnologia, os resultados obtidos até o momento mostram que, em virtude dos altos títulos de anticorpos induzidos pelas proteínas recombinantes produzidas em plantas (proteína E), a proposta é viável e poderá abrir perspectivas para a produção de uma vacina eficaz e de baixo custo contra a dengue (Notas de campo e pesquisa documental).

Unma Thistónila da biotecnologia "Desenvolvinnento de vacinas urtilizando un sistema vegetall como bioffäbrica": carracterizandlo a disisrup p̧ão?

Conforme Clark e Rowlinson (2004), os estudos históricos são, em geral, cronológicos, apresentando um conjunto de narrativas organizadas em períodos distintos e tendo como base os objetivos do estudo. Para este estudo foi estabelecido o período de tempo entre os anos de 2004, marcando o início das atividades de P\&D e processos de patenteamento relacionados à biotecnologia sob estudo, e o ano de 2014, momento em que se iniciam os preparativos para a organização da spin-off Greenbean e de sua rede de atores. Nesse período de 10 anos, entre 2004 e 2014, foram construídos os relatos e enredos que não necessariamente se seguem, mas, ao contrário, se sobrepõem e se confundem entre três períodos de tempo assim caracterizados: i) 2004-2010 - busca de soluções para o problema de saúde pública da dengue; ii) 2005-2012 - processo de patenteamento da biotecnologia sob estudo; iii) 2010-2014 - criação da spin-off Greenbean e de sua rede de atores.

Considerando as motivações que impulsionaram o desenvolvimento da biotecnologia sob estudo na busca de uma solução para o problema da dengue, constatou-se dos relatos da cientista que os exames clínicos comumente realizados (hematócrito e contagem de plaquetas) fornecem informações úteis, mas não comprovam o diagnóstico de dengue, pois a alteração das taxas sanguíneas pode estar atrelada a outras infecções (VARELLA, 2012). De acordo com as notas tomadas durante a pesquisa de campo, entendeu-se que o diagnóstico inicial da dengue ainda é probabilístico, partindo-se do exame físico do paciente e de seu histórico, bem como da exclusão 
de outras doenças, como a doença meningocócica (meningite ou meningococcemia) ou a leptospirose. Além disso, terapêuticas específicas para o tratamento da dengue ainda não estão disponíveis e o único meio de prevenir a doença até o momento é controlar o vetor (SCHMITZ et al., 2011).

Nesse sentido, a cientista-coordenadora do laboratório de P\&D verificou uma lacuna no conhecimento relativa à necessidade de um diagnóstico precoce da dengue:

[...] nossas pesquisas são direcionadas para resolver o problema do diagnóstico precoce da dengue $[\ldots]$ é muito triste você ver as pessoas morrerem de dengue [...] por que ainda não conseguiram diagnosticar eficazmente a dengue? Então eu intuir que o campo de pesquisa da dengue era muito árido e que existia uma lacuna com relação ao desenvolvimento de pesquisa. $O$ que eu percebi nesse momento é que a pesquisa da dengue era voltada para a clínica [...] e o Brasil não estava fazendo nada contra a dengue da maneira como eu via o problema. Então eu comecei experimentos para a produção de anticorpos para desenvolver uma técnica sorológica (Informação verbal).

De acordo com as informações conseguidas na pesquisa documental e confirmadas nas entrevistas, os primeiros projetos voltados ao estudo da dengue se iniciaram no ano de 2004 no Laboratório de P\&D de Bioquímica Humana da UECE/Renorbio, quando a cientista, com base em seus conhecimentos nas áreas de Virologia, Imunologia e Biotecnologia, começou a refletir sobre como poderia desenvolver uma tecnologia, tipo vacina, que solucionasse o problema de saúde pública da dengue. No entanto, o laboratório carecia de recursos, assim, a cientista submeteu projetos para fundos de subvenção, além de conseguir parcerias com institutos e pesquisadores nacionais e internacionais (Notas de campo, pesquisa documental).

A impossibilidade de se fabricar vacina usando os métodos tradicionais decorre do fato de que a doença da dengue se manifesta em quatro sorotipos parecidos, porém diferentes (SCHMITZ, et al., 2011). Esse foi um dos problemas que impulsionou a cientista-coordenadora a refletir diferentemente sobre o problema da dengue: "Nessa época, eu pensei nessa ideia de fazer vacina usando vírus da planta, porque eu concluí através de estudos realizados em virologia e em imunologia que era praticamente impossível produzir vacina usando os métodos tradicionais" (Informação verbal).

Apesar de não se configurar o critério de novidade absoluta, tendo em vista já existir no mercado tecnologia semelhante de produção de vacinas utilizando sistemas vegetais (GHARELO, et al., 2016), ainda não havia vacinas produzidas com vegetais especificamente contra a dengue (Notas de campo, pesquisa prospectiva com o Questel Orbit).

Esses episódios históricos evidenciam que a tecnologia em estudo apresenta uma potencialidade viável, caracterizando um processo vantajoso de produção de vacina contra a dengue. Além disso, conforme relatado nos cadernos de campo, frente ao estado atual da técnica, a tecnologia da produção de vacinas utilizando sistemas vegetais oferece como diferenciais a diminuição considerável dos custos, a simplicidade na produção, a possível produção em alta escala, a redução de reações alérgicas típicas das vacinas desenvolvidas por meio dos métodos tradicionais, como, por exemplo, aquelas que utilizam organismos vivos e vírus atenuados e, por fim, a segurança biológica. Essas potencialidades identificadas na biotecnologia sob estudo se adéquam, portanto, ao conceito proposto por Christensen, Grossman e Hwang (2009) acerca das características das tecnologias disruptivas. Sobre o diferencial da vacina desenvolvida, a cientista-coordenadora relata:

[...] Com a produção de vírus de planta é possível desenvolver uma vacina pra dengue via oral, sem adjuvante por uma via natural, não é agressiva, por ser uma vacina fitoterápica produzida em planta. Ela não tem efeito colateral, não tem proteínas tóxicas, quer seja na folha de feijão, quer seja na folha de boldo. É uma vacina que usa uma tecnologia simples, mas, altamente avançada, então por que não apostar nessa vacina? (Informação verbal).

Por ser produzida utilizando um sistema vegetal como biofábrica, a referida vacina possui um alto grau de pureza, diminuindo os custos de produção (GHARELO et al., 2016). Ainda, por ser uma tecnologia limpa, a pesquisa foi reconhecida como 
uma das cem tecnologias de destaque para a criação de uma economia verde no século 21 pelo Bright green book - Livro verde do século 21 (BRIGHT, 2013). De acordo com a cientista, uma única planta (Vigna Unguiculata) pode gerar inúmeras doses de vacina, além disso, seu custo de produção é aproximadamente $75 \%$ mais barato do que o preço do principal concorrente, isso considerando o valor de produção da proteína necessária para a vacina contra a dengue. Nesse sentido, infere-se sobre as possibilidades para a formulação e o fomento de políticas públicas na área da saúde voltadas para a prevenção da dengue, haja vista os altos gastos governamentais com o tratamento da doença. No ano de 2013, o Brasil gastou R\$ 2 bilhões com a doença, e sofreu o maior surto com aproximadamente dois milhões de casos notificados (BRASIL, 2016).

A partir desse intervalo de tempo, coincidindo com o patenteamento da biotecnologia sob estudo em 2011, a análise dos relatos e dos documentos históricos evidenciaram que o investimento nessa biotecnologia de produção de vacinas utilizando sistemas vegetais articula construtos importantes que se deslocam entre a primeira dimensão - capacitador tecnológico (tecnologia sofisticada que tem por intuito simplificar), uma vez que se inferem potencialidades economicamente viáveis, simples, sustentáveis, que possam vir a proporcionar maior acessibilidade à saúde ao contribuir para uma medicina de precisão no caso da dengue (CHRISTENSEN; GROSSMAN; HWANG, 2009).

Em um segundo momento da pesquisa, e considerando os procedimentos de codificação aberta (COFFEY; ATKINSON, 1996) realizados nos documentos que compuseram o corpus histórico, algumas passagens foram evidenciadas, envolvendo o período de tempo entre os anos de 2011 e 2014 e caracterizando os processos de negociação do patenteamento da biotecnologia, da criação da spin-off Greenbean e das tentativas de organizar uma rede de atores.

Após o depósito do pedido de patente em 2011, processo que permite a definição da invenção e negociação da identidade tecnológica da biotecnologia, houve grande repercussão na imprensa, despertando o interesse da Fundação Oswaldo Cruz (Fiocruz). A Fiocruz, que, à época, estava prestes a fechar uma parceria de seis bilhões de reais com uma instituição de pesquisa de Israel (Franhauber - Chemical Process Software) para o desenvolvimento de uma vacina contra a dengue, entrou em contato com a cientista, visando melhor conhecer a biotecnologia sob estudo. Diante disso e durante esse período, acompanhou-se a negociação com a Fiocruz sobre as questões relacionadas à realização dos testes clínicos e comercialização da biotecnologia, haja vista essa instituição possuir uma importante infraestrutura para esses fins (Notas de campo).

Considerando o caráter tácito e o longo prazo de maturidade dos projetos em biotecnologia (HARPUM, 2010), nota-se aqui uma questão relacionada ao maior obstáculo a ser vencido, qual seja, a implementação de ferramentas eficazes de gestão que auxiliem o lançamento da P\&D no mercado. Verificou-se das entrevistas com a cientista e com o coordenador da Redenit que, para a comercialização da biotecnologia, tornou-se importante a constituição de uma rede com a busca de novas alianças institucionais, com o intuito de facilitar a realização dos testes clínicos, tendo em vista a comercialização da biotecnologia.

Esses eventos acerca da ampliação da rede com a entrada de novos atores, como a Redenit, a Fiocruz e outros possíveis mercados na arena das negociações, coadunam com alguns dos construtos que caracterizam a segunda dimensão de disrupção elencada pelos autores que versam sobre inovação do modelo de gestão. Para Christensen (2012), após a identificação de um capacitador tecnológico, é necessário que seja elaborada uma estratégia adequada para a sua comercialização, voltando-se assim os esforços para a análise do contexto organizacional. Nesse ponto, avalia-se o modelo de gestão mais estratégico, entre os quais o autor cita a criação de uma nova organização (CHRISTENSEN, 2012).

Contudo, os relatos evidenciaram alguns desafios e dificuldades, pois, até o final desta pesquisa em 2014, e corroborando os construtos acerca da segunda dimensão dos processos disruptivos relacionada ao modelo de gestão (CHRISTENSEN, 2012), 
as negociações com a Fiocruz ainda estavam em processo, sobretudo em relação à necessidade da realização dos testes clínicos, sendo esta uma das exigências mais dispendiosas para que uma nova tecnologia consiga chegar ao atual estágio da vacina sob estudo (Entrevistas com o coordenador da Redenit).

Infere-se, portanto, que o laboratório de P\&D da Renorbio ainda não reuniu alianças estratégicas - científicas, econômicas e políticas - suficientes para a concretização dos testes clínicos e, consequentemente, concretizar a produção da vacina em escala comercial.

No entanto, no último período de tempo em análise entre os anos de 2010-2014, observou-se dos enredos que esforços estão sendo envidados para a ampliação da rede, com o envolvimento de novas instituições, como o Governo do estado, visando à reforma do laboratório de $\mathrm{P} \& \mathrm{D}$ da Renorbio, sendo essa uma das condições para a ativação da participação da Fiocruz e, consequentemente, inovar no modelo de gestão então vigente (CHRISTENSEN, 2012).

Apesar dos desafios, relata-se que as negociações envolvendo a cientista em parceria com a Redenit/CE resultaram no desenvolvimento de diferentes estratégias para a comercialização de kits de biotecnologia diferenciados, possibilitando a exploração de novas oportunidades de negócio. Assim, foi discutida a criação de uma spin-off - a Greenbean - com o objetivo de gerar condições futuras, bem como para a facilitação de que outros procedimentos em biotecnologia, desenvolvidos pelo laboratório de P\&D da Renorbio, cheguem ao mercado, diminuindo o gap entre a pesquisa desenvolvida nos institutos científicos e sua aplicação nos setores produtivos. Enfim, no ano de 2013 foi definitivamente criada uma nova empresa do tipo spin-off, a Greenbean, instalada na incubadora de empresas da UECE, atuando nas áreas de biotecnologia, imunologia, microbiologia, bioquímica e biologia molecular. A Greenbean possui tecnologia para a produção de proteínas transientes recombinantes para o desenvolvimento de kits de diagnósticos, bem como desenvolve alimentos funcionais para atender aos mercados humano e animal (GREENBEAN, 2013).

Atualmente, a Greenbean é uma spin-off registrada, funcionando na incubadora da UECE, com atuação experimental e sendo preparada estrategicamente para uma futura produção em escala comercial. Para isso, estão sendo articuladas novas parcerias na ampliação dessa rede emergente com instituições de fomento e outros investidores do setor para garantir o aporte financeiro (Relatos da representante comercial da Greenbean).

Conforme anteriormente discutido, constata-se que as estratégias de formação e ampliação dessa rede institucional de suporte ao desenvolvimento, com o intuito de comercialização da biotecnologia, continuam sendo articuladas, alinhando-se à proposta de Christensen (1997) no que se refere à dimensão da inovação no modelo de gestão, ante uma tecnologia potencialmente disruptiva. Além disso, esses relatos relacionados com a criação da Greenbean e a entrada de novos atores estão de acordo com a compreensão dos processos tecnológicos enquanto processos sociais, resultantes de complexas redes de relações entre diferentes agentes influenciadores, sejam institucionais, econômicos ou tecnológicos (RABINOW, 2002; GODIN, 2008; IPIRANGA, 2010; HOHOLM; ARAÚJO, 2011).

Esses relatos se coadunam com as colocações de Christensen (2012), quando enfatiza que as empresas pequenas e independentes (tipo as spin-offs) seriam apropriadas quando se confronta com uma tecnologia disruptiva, uma vez que possuem uma forma de organização especialmente dedicada a uma futura adaptação à rede de valor que poderá emergir. Além de Christensen (1997), a criação da spin-off Greenbean vem ao encontro das discussões colocadas por Rose (2012), ao fazer referência à "economia da vitalidade", evidenciando que os atores anteriores, como as grandes corporações farmacêuticas, transformaram-se como resultado de suas relações com a ciência, surgindo nesse processo novos atores, como as empresas emergentes tipo spin-off de biotecnologia.

Por outro lado e apesar dessas colocações, no que se refere à terceira dimensão disruptiva elencada por Christensen, Grossman e Hwang (2009) - novo sistema de valor 
comercial -, e com base nos relatos prospectivos (SILOBREAKER, 2013), verificou-se que o sistema comercial da área de vacinas é constituído por grandes empresas farmacêuticas que formam uma estrutura oligopólica de alto nível de competição e concorrência, com gastos de P\&D e volume de vendas na cifra de bilhões de dólares anuais. Atualmente, as seis principais empresas que dominam mundialmente o setor são: Novartis, Sanofi Pasteur, Merck, Roche, Sandoz, Lilly e Glaxo (GREENBEAN, 2013).

No caso da dengue, as tentativas de produção estão espalhadas pelo mundo, envolvendo iniciativas das instituições de saúde, da gigante farmacêutica Sanofi Pasteur AS, bem como de P\&D no Brasil, Estados Unidos, Japão, Índia, Tailândia e Filipinas (SILOBREAKER, 2013). Acontece que muitas dessas tentativas de produção de vacinas partem do vírus atenuado, estando em fase de testes, com a ocorrência de testes fracassados e efeitos colaterais, como mostrado no artigo do Medical News Today (EARLY-STAGE, 2013).

Portanto, no panorama nacional e internacional, há a distribuição de vacinas mais tradicionais de baixo custo, e as modernas com um custo mais elevado, sendo, portanto, mais restritas. De acordo com a representante comercial da Greenbean, "a capacidade competitiva dos produtores nacionais se mostra baixa, em comparação com os competidores internacionais". Esses relatos indicam a ausência de evidências dos construtos relacionados à dimensão sistema de valor comercial, obstando a realização disruptiva da tecnologia sob estudo em todo o seu potencial.

Essa última dimensão consiste na organização de uma cadeia de valor vinculada aos modelos de gestão existentes e/ou emergentes. Os relatos descrevem as dificuldades de negociações com as grandes e mesmo pequenas corporações do setor farmacêutico, corroborando que o ponto mais difícil é conseguir mover os atores líderes, alterando a configuração do sistema comercial então vigente (CHRISTENSEN, 2012).

Enfim, os relatos e enredos históricos produzidos no decorrer desse período de tempo, 2004-2014, acerca da biotecnologia sob estudo indicam que essa tecnologia reúne características que enfatizam, sobretudo, os construtos disruptivos da dimensão capacitador tecnológico. Por outro lado, observou-se ainda do estudo histórico que algumas características do desenvolvimento da biotecnologia transitam entre alguns construtos da dimensão disruptiva inovação do modelo de gestão, ao oferecer potenciais soluções que podem vir a caracterizar disponibilidade e acessibilidade, sobretudo com a criação de uma nova empresa do tipo spin-off e pela ampliação de uma rede reunindo diferentes atores, proporcionando um valor (the value proposition) em termos de produtos e serviços (CHRISTENSEN, 2012; DECLEYN; BRAET, 2009; KIM; MAUBORGNE, 2005).

Contudo, considera-se que os construtos principais que compõem a dimensão inovação do modelo de gestão são ainda limitantes para a realização de uma disrupção em todo o seu potencial, uma vez que não foi evidenciada uma ampla alocação de recursos (resources) e dos processos organizacionais (processes) para a organização de uma significativa rede de valor, envolvendo diferentes atores, materiais, instalações, aportes financeiros e estrutura de custos (profit formula), produtos, equipamentos, treinamentos, padrões, que identificasse essa potencialidade disruptiva em sua plenitude (CHRISTENSEN; GROSSMAN; HWANG, 2009).

\section{Cornclursão}

Esta pesquisa buscou assinalar como profícuo o uso dos pressupostos metodológicos da análise histórica no que se refere ao estudo do potencial disruptivo de tecnologias, tendo como intuito responder à questão: qual o potencial disruptivo da biotecnologia "Desenvolvimento de vacinas utilizando um sistema vegetal como biofábrica"? Essa biotecnologia foi produzida no Laboratório de P\&D de Bioquímica Humana da Universidade Estadual do Ceará, integrado à Rede Nordeste de Biotecnologia (Renorbio).

Para Christensen, Grossman e Hwang (2009), o processo de disrupção é constituído por três dimensões principais que possibilitam que problemas fundamentais 
de um setor sejam tratados a menores escala, custo e capacidade humana do que o comumente exigido: capacitador tecnológico, modelo de gestão e sistema de valor comercial. Nessa linha, investigou-se a história do potencial disruptivo da biotecnologia, tendo como base as evidências dos construtos que caracterizam essas dimensões.

Utilizando a história enquanto método, os relatos e enredos construídos consideraram o período de 10 anos, envolvendo os anos de 2004 a 2014, transitando entre três períodos de tempo assim caracterizados: i) 2004-2010 - busca de soluções para o problema de saúde pública da dengue; ii) 2005-2012 - processos de patenteamento da biotecnologia sob estudo; iii) 2010-2014 - criação da spin-off Greenbean e de sua rede de atores.

Como resultados, e considerando os construtos básicos que fundamentam as tecnologias disruptivas, argumenta-se que a biotecnologia sob estudo justifica a sua potencialidade de disrupção ao articular os construtos relacionados à dimensão do capacitador tecnológico.

Diferentes e diversos episódios históricos confirmaram essa evidência quando enfatizaram as características da biotecnologia em estudo ao utilizar um sistema vegetal como biofábrica. Esse tipo de tecnologia da produção de vacinas utilizando sistemas vegetais oferece como diferenciais a diminuição considerável dos custos, a simplicidade na produção, a possível produção em alta escala e a segurança biológica com a redução de reações alérgicas (GHARELO et al., 2016). Concluiu-se, portanto, que essas potencialidades identificadas na biotecnologia se adéquam ao conceito proposto por Christensen, Grossman e Hwang (2009) acerca das características das tecnologias disruptivas e, em particular, aos construtos relativos à primeira dimensão do capacitador tecnológico.

Por outro lado, observou-se que alguns fragmentos dos relatos históricos da biotecnologia transitaram entre os construtos da dimensão disruptiva inovação do modelo de gestão, sobretudo após a criação de uma nova empresa do tipo spin-off - a Greenbean - que possibilitou o desenvolvimento de diferentes estratégias para a comercialização de kits de biotecnologia diferenciados e a exploração de novas oportunidades de negócio.

Contudo, considerou-se que esses construtos evidenciados na pesquisa que compõem a dimensão inovação do modelo de gestão são limitantes. Os fragmentos relacionados a essas lacunas foram evidenciados na análise dos processos de criação de uma rede, envolvendo diferentes atores, além da Redenit e da Fiocruz, que visavam a realização dos testes clínicos da biotecnologia. Nesse ponto, refletiu-se sobre a necessidade de ampliação e consolidação dessa rede de relações entre atores e agentes influenciadores, sejam institucionais, econômicos ou tecnológicos. Inferiu-se que essas ações possibilitariam que a Greenbean ultrapassasse a sua atuação experimental e concretizasse a produção escalar da biotecnologia, diminuindo, consequentemente, o gap entre a pesquisa desenvolvida nos institutos científicos de P\&D e a sua aplicação nos setores produtivos.

Por fim, observou-se da análise histórica a ausência de evidências dos construtos relacionados à dimensão sistema de valor comercial, obstando a realização de uma ruptura em todo o seu potencial. Essas evidências indicaram os grandes desafios em organizar uma cadeia de valor, envolvendo as pequenas e grandes corporações do setor farmacêutico, no sentido de alterar a configuração do sistema comercial então vigente.

Como contribuição deste estudo, releva-se a discussão teórica e metodológica acerca dos processos tecnológicos disruptivos com a utilização da abordagem histórica enquanto método. Enfatiza-se, portanto, a relevância do uso da abordagem histórica no estudo de práticas científicas, ao iluminar os entrecruzados caminhos entre a "versão oficial" da história escrita nos variados tipos de documentos tecnológicos, a versão "não oficial" relatada pelos atores envolvidos e as "histórias" acerca da utilização efetiva das tecnologias. Conforme evidenciado, os relatos contidos nos relatórios "oficiais" que são elaborados de objetos tecnológicos (tipo as patentes, por exemplo) têm petrificado o processo da ciência e tornaram-se armas nos arsenais da indústria baseada na ciência (BOWKER, 1992). Nesse sentido, os estudos históricos 
que focalizam os caminhos tortuosos que esses atores e objetos perfizeram, tornam-se fundamentais na produção e socialização desse conhecimento embutido nas práticas e tecnologias produzidas nos laboratórios científicos de redes acadêmicas e/ou nos departamentos de P\&D de empresas.

Acentua-se ainda que a inserção da perspectiva histórica na administração contribui para o avanço da área, uma vez que promove maior reflexividade na geração interdisciplinar de novas abordagens e novos olhares, relacionados a diferentes objetos de estudo, entre os quais as práticas científicas e os processos tecnológicos e de inovação.

Sobre tudo o que se expôs, espera-se que novas pesquisas possam aprofundar a análise realizada nesta investigação, utilizando, por exemplo, a abordagem da teoria ator-rede (TAR) (actor network theory - ANT) para o estudo da spin-off e do organizar da sua rede sociotécnica, focalizando os obstáculos e desafios das translações de uma tecnologia até a sua comercialização no mercado, concluindo, assim, o processo de inovação.

A análise dos processos tecnológicos no setor de biotecnologia, principalmente no que se refere às inovações disruptivas em economias latecomers, é um tema que ainda está longe de ser esgotado. Sendo assim, esta pesquisa representa um esforço inicial de construção de uma agenda de pesquisa para esses temas, utilizando abordagens teóricas interdisciplinares com ênfase na historiografia da ciência, tecnologia \& inovação (C,T\&I).

Referêncials

ADNER, R. When are technologies disruptive? A demand-based view of the emergence of competition. Strategic Management Journal, p. 667-688, 2002.

ALVESSON, M.; SANDBERG, J. Generating research questions through problematization. Academy of Management Review, v. 36, n. 2, p. 247-271, 2011.

BARNES, B.; BLOOR, D.; HENRY, J. Scientific knowledge. A sociological analysis. Chicago: The University of Chicago Press, 1996.

BARROS, A. Os arquivos e o "arquivo" (e vice-versa): temas para os estudos organizacionais. In: ENCONTRO DA ASSOCIAÇÃO NACIONAL DOS PROGRAMAS DE PÓS-GRADUAÇÃO EM ADMINISTRAÇÃO, 38., 2014, Rio de Janeiro, Anais... Rio de Janeiro, 2014a.

BARROS, A. Uma narrativa sobre os cursos superiores em Administração da FACE/ UFMG: dos primeiros anos à sua unificação em 1968. Cad. EBAPE.BR, Rio de Janeiro, v. 12, n. 1, mar. 2014b.

BARROS, A.; CARRIERI, A. P. O cotidiano e a história: construindo novos olhares na Administração. $R A E$, v. 55, n. 2, p. 151-161, mar./abr. 2015.

BOOTH, C.; ROWLINSON, M. Management and organizational history: prospects. Management \& Organizational History, v. 1, n. 1, p. 5-30, 2006.

BOWER, J. L.; CHRISTENSEN, C. M. Disruptive technologies: catching the wave. Harvard Business Review, v. 73, n. 1, p. 45-53, 1995.

BOWKER, G. What's in a patent? In: BIJKER, W. E.; LAW, J. Shaping technology building society. Studies in sociotechnical change. Massachusetts Institute of Technology, 1992. p. 53-74.

BRASIL. Ministérios da Saúde. Dengue. Disponível em: <http://portalsaude.saude. gov.br/index.php/o-ministerio/principal/secretarias/svs/dengue>. Acesso em: 9 ago. 2016.

BRIGHT Green Book. Vacina contra a dengue produzida do feijão. 2013. Disponível em: <https://pt.scribd.com/document/87290526/Bright-Green-Book-2011>.

Acesso em: 26 mar. 2018. 
CALLON, M. Introduction in la science et ses réseaux: genèse et circulation des faites scientifique. Paris: La Découverte; Unesco, 1989. p. 7-33.

CHRISTENSEN, C. M. Dilema da inovação: quando as novas tecnologias levam empresas ao fracasso. São Paulo: M. Books do Brasil, 2012.

CHRISTENSEN, C. M. The innovator's dilemma: when new technologies cause great firms to fail. Cambridge, MA: Harvard Business School Press, 1997.

CHRISTENSEN, C. M.; GROSSMAN, J.; HWANG, J. The innovator's prescription: a disruptive solution for health care. New York: McGraw-Hill, 2009.

CHRISTENSEN, C. M.; RAYNOR, M. E. The innovator's solution. Harvard: Business School Press, 2003.

CLARK, P.; ROWLINSON, M. Time and narrative history: chattering historical narratives. Denver: Academy of Management Meeting; Organization and Management History Division, Aug. 2004.

COFFEY, A.; ATKINSON, P. Making sense of qualitative data. London: Sage, 1996.

COOKE, B. Writing the left out of management theory: the historiography of the management of change. Organization, v. 6, n. 1, p. 81-105, 1999.

COSTA, A. S. M. da; BARROS, D. F.; MARTINS, P. E. Perspectiva histórica em administração: novos objetos, novos problemas, novas abordagens. Revista de Administração de Empresas, v. 50, n. 3, p. 288-299, jul./set. 2010.

CROCE, B. História e crônica. In: GARDINER, P. Teorias da história. Lisboa: Calouste Gulbenkian, 2004.

DECLEYN, S.; BRAET, J. Research valorization through spin-off ventures:

integration of existing concepts and typologies. World Review of Entrepreneurship, Management and Sustainable Development, v. 5, n. 4, p. 325-352, 2009.

EARLY-STAGE Trial of Nih-Developed Candidate Dengue Vaccine Shows Promise. Medical News Today, 25 jan. 2013. Disponível em: <http://www.medicalnewstoday. com/releases/255346.php>. Acesso em: fev. 2014.

FUNDAÇÃO BIOMINAS. Estudo de empresas de biotecnologia do Brasil. Belo Horizonte: Fundação Biominas, 2011.

GHARELO, R. S. et al. Production of therapeutic proteins through plant tissue and cell culture. BioSci. Biotech, v. 5, n. 1, p. 93-104, 2016.

GILL, F; ELDER, C. Data and archives: the internet as site and subject.

International Journal of Social Research Methodology, v. 15, n. 4, p. 271-279, July 2012.

GODIN, B. Innovation: the history of a category. Project on the Intellectual History of Innovation, Working Paper, Canadá: Montreal, n. 1, 2008.

GODIN, B. The linear model of innovation: the historical construction of an analytical framework. Science, Technology and Human Values, v. 31, n. 6, p. 639-667, 2006.

GODIN, B. Writing performative history: the new 'New Atlantis'. Social Studies of Science, v. 28, n. 3, p. 465-483, 1998.

GREENBEAN Biotechnology. Apresentação institucional. Fortaleza, 2013. 1 CDROM.

GUEDES, M. I. F. et al. Processo de produção de proteínas do vírus da dengue em plantas, e uso de proteínas na preparação de vacina contra a dengue. Pedido de patente: PI 1100532-7 A2, 16 fev. 2011, 2 out. 2012.

HARPUM, P. (Ed.) Portfolio, program, and project management in the

pharmaceutical and biotechnology industries. New Jersey: John Wiley \& Sons, 2010. 
HENDERSON, R. M.; CLARK, K. B. Architectural innovation: the reconfiguration of existing product technologies and the failure of established firms. Administrative Science Quaterly, v. 35, n. 1, p. 9-30, 1990.

HITT, M. A. Empreendedorismo e inovação corporativa. In: HITT, M. A. Administração estratégica. São Paulo: Pioneira Thomson Learning, 2005. p. 520547.

HOHOLM, T.; ARAÚJO, L. Studying innovation processes in real-time: the promises and challenges of ethnography. Industrial Marketing Management, v. 40, n. 6, p. 933-939, 2011.

IPIRANGA, A. Uma discussão sobre a cultura científica da biotecnologia: as relações da academia com a ciência industrial e o governo. REGE - Revista de Gestão da USP, v. 17, p. 371-385, 2010.

IPIRANGA, A. S. R.; MATOS, L. B. S. As práticas científicas em um laboratório de biotecnologia: uma discussão sob a ótica da teoria ator rede. In: ENCONTRO DE ESTUDOS ORGANIZACIONAIS, 8., 2014, Gramado. Anais... Gramado, 2014.

JONES, G.; ZEITLIN, J. The Oxford handbook of business history. UK: Oxford University Press, 2007.

KIM, W. C.; MAUBORGNE, R. A estratégia do oceano azul. Rio de Janeiro: Elsevier, 2005.

OMS. Organização Mundial da Saúde. World Health Day 2014: small bite, big threat. Disponível em: <http://www.who.int/campaigns/world-health-day/2014/ en/>. Acesso em: set. 2013.

RABINOW, P. Making PCR. A story of biotechnology. Chicago: The University Chicago Press, 2002.

RENORBIO. Rede Nordeste de Biotecnologia. Desenvolvido por Renorbio (2005-2010), 2013.

ROSE, N. Politicas de la vida. Biomedicina, poder y subjetividad em el siglo XXI. La Plata: Unipe Editorial Universitaria, 2012.

ROSENBERG, N. Por dentro da caixa-preta: tecnologia e economia. Campinas: Editora da Unicamp, 2006.

SCHMITZ, J. et al. Next generation dengue vaccines: a review of candidates in preclinical development. US National Library of Medicine - National Institutes of Health, v. 29, n. 42, p. 7276-84, 23 set. 2011. Disponível em: <http://www.ncbi. nlm.nih.gov/pubmed/21781998>. Acesso em: 8 ago. 2016.

SILOBREAKER. Brazil dengue vaccine. 2013. Disponível em: <https://www. silobreaker.com/>. Acesso em: 26 mar 2018.

SPRADLEY, J. P. The ethnographic interview. New York: Holt, Rinehart and Winston, 1980.

ÜSDIKEN, B.; KIESER, A. Introduction: history in organization studies. Business History, v. 46, n. 3, p. 321-330, 2004.

VARELLA, D. Dengue: quadro clínico, diagnóstico e tratamento. 2012. Disponível em: <http://drauziovarella.com.br/wiki-saude/dengue-quadro-clinico-diagnosticoe-tratamento/>. Acesso em: 16 mar. 2018.

VIZEU, F. Potencialidades da análise histórica nos estudos organizacionais brasileiros. RAE (Impresso), v. 50, p. 36-46, 2010.

\section{Submissão: 07/04/2016 \\ Aprovação: 28/09/2016}

